\title{
MANAGING ONLINE SERVICE RECOVERY: PROCEDURES, JUSTICE AND CUSTOMER SATISFACTION
}

Jaywant Singh and Benedetta Crisafulli

\section{Author Details}

Author 1 Name: Dr Jaywant Singh Department: Strategy, Marketing and Innovation University/Institution: Kingston University Town/City: London KT2 7LB

Country: United Kingdom

Author 2 Name: Benedetta Crisafulli Department: Strategy, Marketing and Innovation University/Institution: Kingston University Town/City: London KT2 7LB

Country: United Kingdom

Corresponding author: Dr Jaywant Singh

Corresponding Author's Email: J.Singh@kingston.ac.uk

This article is (c) Emerald Group Publishing and permission has been granted for this version to appear here http://eprints.kingston.ac.uk . Emerald does not grant permission for this article to be further copied/ distributed or hosted elsewhere without the express permission from Emerald Group Publishing Limited. 


\section{Structured Abstract}

\section{Purpose}

The Internet has changed the way services are delivered and has created new forms of customer-firm interactions. Whilst online service failures remain inevitable, the Internet offers opportunities for delivering efficient service recovery through the online channel. Notwithstanding, research evidence on how firms can deliver online service recovery remains scarce. This study investigates the impact of two online service recovery strategies - online information and technology-mediated communication - on customer satisfaction, switching and word-of-mouth intentions.

\section{Design/methodology/approach}

A scenario-based experiment is employed. Data are analysed using partial least squares structural equation modeling (PLS-SEM).

\section{Findings}

Online information and technology-mediated interactions can be used as online service recovery strategies. When fair, online service recovery can restore customer satisfaction, lower switching and enhance positive word-of-mouth. Interactional justice delivered through technology-mediated communication is a strong predictor of satisfaction with online service recovery. Yet, customers in subscription services show greater expectations of online service recovery than those in non-subscription services.

\section{Research limitations/implications}

Further research could examine the impact of online service recovery on relational constructs, such as trust. Since customers participate in the online recovery process, future research could investigate the role of customers as co-creators of online service recovery.

\section{Practical implications}

Service managers should design online recovery strategies that meet customer need for interactional justice, for example, bespoke emails, and virtual chat communications showing genuine customer care.

\section{Originality/value}

Online information and technology-mediated communication function as online service recovery strategies. Customer perceptions of justice towards online service recovery restore satisfaction, and encourage loyal behaviour.

Keywords: online service failure and recovery, perceived justice, experiment, PLS-SEM

Article Classification: Research paper 


\section{Introduction}

Advancements in information technology have notably changed the way in which customer-firm interactions take place and services are delivered. Through the use of modern technology, services can be provided over long distances and without the physical presence of customers and employees (Schumann et al., 2012). Consumers are increasingly becoming accustomed to online services and technology-mediated interactions. Through the Internet, consumers buy flight tickets, undertake training courses, handle money transfers and undertake online consultations with service providers. Online shopping is facilitated by technological innovations, such as broadband connection, which have made the Internet accessible to all consumers. In the UK alone, recent estimates show that 87 per cent of consumers have Internet broadband connection at home, and when asked, 90 per cent of consumers report shopping online in the past three months (Mintel, 2015). In the online retail sector, in particular, sales of clothing and accessories are estimated to have reached the value of $£ 10.7$ billion in 2014 , equivalent to more than 17 per cent of the total spending on clothing and accessories (Mintel, 2014). The Internet therefore provides unparalleled opportunities for firms, especially for firms operating in the retail sector. After USA, UK is the secondlargest online retail market in the world with an estimated value of $£ 48.51$ bn (Key Note, 2013).

The increasing importance of the Internet in consumer purchasing decisions has led to a growing body of research. Research in this domain has so far addressed a variety of issues, such as the measurement of e-service quality (Parasuraman et al., 2005), customer use of self-service technologies (Meuter et al., 2005), and customer delight with online services (Bartl et al., 2013). Empirical research on consumer perceptions of online service failure and recovery, however, is surprisingly scarce despite the fact that service failures, both offline and online, are inevitable events for service firms. Crucially, online service failures can have 
a negative impact on firms' profitability. Holloway and Beatty (2003) suggest that customers complain online more than offline. For consumers, the Internet offers a platform where complaining is effortless yet impactful, wherein a wide and geographically dispersed audience can be reached. For firms, online complaints can pose a threat to their reputation in the marketplace. This is confirmed by the growth of online consultancies (e.g., www.Igniyte.com) that work with businesses to monitor and manage online consumergenerated content. Further, consumers may consider alternative service providers following service failures. It is estimated that 66 per cent of buyers do not visit the same service provider after a service failure, especially if the failure is followed by unsatisfactory recovery (MarketingCharts Staff, 2013). Compared to offline, switching is easier on the Internet, where customers can browse and look for alternative providers with the click of a mouse. Given the above background, gaining an understanding of how to manage online service failures effectively is crucial to the success of firms operating online.

Extant research mainly investigates customer reactions to service failure and recovery encounters taking place at brick and mortar outlets (i.e. offline). Studies in this domain stress the importance of fair (or just) service recovery in restoring customer satisfaction following offline service failures (e.g., Tax et al., 1998; Smith et al., 1999; Sparks and McCollKennedy, 2001; Roschk and Kaiser, 2013). Studies focusing on service failures in virtual outlets examine how such negative encounters are rectified by offline service recovery. For instance, Harris et al. (2006) investigate how customer responses to recovery compensation vary depending on whether online or offline service failures are encountered, but without considering customer perceptions of justice despite their relevance. Holloway et al. (2005) and Lin et al. (2011), on the other hand, examine customer perceptions of justice towards offline service recovery attempted following online service failures. Notwithstanding, these studies do not take into account how firms use online tools in order to deliver online service 
recovery, and the impact of online service recovery on customer perceptions and subsequent behaviour. In practice, firms encourage customers to actively participate in the service recovery encounter by employing a variety of online tools, such as online instruction pages and virtual chat features. Knowledge on how to design such online tools is crucial for online service providers to be able to manage service recovery efficiently.

Attempting to address the above research gap, the present study investigates customer perceptions of justice, satisfaction and subsequent behavioural intentions in the context of online service failure and recovery encounters. The aim of the study is to understand how online tools can be used to deliver fair service recovery and to restore customer-firm relationships. Specifically, the objectives of the study are twofold: a) to examine how two popular online tools, namely online information (i.e. online help pages, Frequently Asked Questions or FAQs) and mode of contact (i.e. technology-mediated interactions through virtual chat, emails), can be used as service recovery strategies and how these impact customer perceptions of justice, and in turn, satisfaction, intentions to switch or to generate positive word of mouth (PWOM); and b) to detect differences in customer responses to online service recovery between subscription (mobile airtime) and non-subscription (online retailing) services.

This study presents important implications for researchers and service managers. Firms increasingly employ online tools such as FAQs and virtual chats as service recovery strategies to manage customer complaints, and ultimately, to foster customer retention. However, introducing FAQs and virtual chat features without prior knowledge on their effectiveness as recovery tools may result in the delivery of unsatisfactory service recovery, and lead to double deviation scenarios (Bitner et al., 1990). In particular, given the established importance of fairness perceptions in offline service recovery encounters, it is imperative that firms understand the impact of online information, provided through FAQ 
pages, and technology-mediated communication, such as virtual chats and emails, on customer perceptions of fairness. The present study examines the effects of online information and technology-mediated communication on customer perceived fairness, with a focus on understanding what makes online service recovery successful. The impact of perceived fairness towards online service recovery on customer satisfaction and postrecovery intentions is also examined. As a result, the study's findings further understanding on the efficacy of service recovery strategies delivered online.

Further, the study attempts to establish the efficacy of the well-known justice framework for explaining customer responses to online service failures followed by online recovery. Although prior research examines perceived justice (fairness) towards offline service recovery efforts (e.g., Tax et al., 1998; Smith et al., 1999; del Río-Lanza et al., 2009), perceptions of justice relating to online service recovery strategies are not addressed yet. Research in this area is vital for service managers to help them establish first, whether online recovery tools convey justice and second, if perceived justice of online service recovery translates into customer satisfaction and loyalty.

Lastly, the study proposes a key distinction between subscription and nonsubscription markets in order to add insights on how customer perceptions of online service failure and recovery, and subsequent behaviour, are influenced by the service context under investigation. In general, knowledge emerging from this study will fuel further research, and inform the decisions of service managers and information technology experts in designing online service recovery strategies.

The remainder of this paper is organised as follows. In the next section, the theoretical underpinnings and research hypotheses for the study are discussed. Next, the methods employed in the study, analysis and research findings are presented. Finally, the 
implications for theory and practice are discussed, along with the limitations of the study, and propositions for future research.

\section{Theoretical Background and Hypotheses Development}

The study is underpinned by the well-known justice theory (Homans, 1961), a widely used framework in service recovery research (e.g., Tax et al., 1998; Smith et al., 1999; Chebat and Slusarczyk, 2005; del Río-Lanza et al., 2009). In a recovery context, customers are shown to evaluate the justice rendered by the firm in offering compensation (distributive justice), in the process of rectifying the service failure (procedural justice) and in customeremployee interactions (interactional justice). Extant research has extensively examined customer perceptions of justice following offline service failure and recovery encounters. In a departure from past research, the present study investigates perceived justice towards service recovery delivered online. Since prior research suggests that service recovery is effective when fair (or just), testing customer perceptions of justice towards online service recovery, and their impact on customer post-recovery behaviour, is important and a key objective of the present study.

Recovery compensation is typically delivered offline, hence related customer perceptions of distributive justice are not expected to differ depending on whether offline or online service failures occur. By contrast, recovery procedures and interactions can take place online. This study therefore focuses on customer perceptions of justice conveyed by online recovery procedures and interactions. Specifically, FAQs and discussion forums entail online procedures of handling service recovery; these are expected to convey the timeliness and efficacy of the firm's online recovery processes, thus procedural justice. Emails and virtual chats entail online, technology-mediated interactions taking place during the recovery 
encounter; these are expected to convey the firm's concern about resolving the service failure, empathy and politeness, thus interactional justice. Procedural and interactional justice perceptions towards online service recovery are, in turn, expected to impact customer satisfaction and consequent behavioural intentions. The theoretical underpinnings and research hypotheses for the study are discussed below.

The impact of perceived justice towards online service recovery on customer satisfaction

Procedural justice stems from the study of legal disputes resolution and its main proponents are Thibaut and Walker (1975). Procedural justice relates to perceptions that the processes followed in delivering outcomes are fair. In a service recovery situation, procedural justice entails customer perceptions of whether the processes followed by the firm in rectifying the service failure are fair (or unfair). Prior research has extensively examined the role of procedural justice in the context of offline service failure and recovery encounters. In this context, customers report perceptions of procedural justice when recovery procedures are flexible and result in a timely resolution of the service failure (e.g., Tax et al., 1998; Chebat and Slusarczyk, 2005; Karatepe, 2006; del Río-Lanza et al., 2009). In turn, perceptions of procedural justice lead to customer satisfaction, and intentions to repatronise the firm and generate positive word of mouth (PWOM) (e.g., Smith et al., 1999, Maxham and Netemeyer, 2002).

By contrast, research thus far has directed little attention towards examining customer perceptions of procedural justice in the context of online service and recovery encounters. In this domain, studies have investigated customer responses to justice-based service recovery strategies delivered offline, even following online service failures. For instance, Shapiro and Nieman-Gonder (2006) examine the role of compensation and apology following online 
service failures. Whilst offering relevant insights on the individual and combined effect of distributive and interactional justice, the above study does not account for the role of procedural justice. Procedural justice is, nonetheless, relevant in both offline and online service recovery encounters, as processes are inevitably involved when attempting to rectify a service failure. Confirming the importance of justice perceptions in a service failure and recovery context, Lin et al. (2011) investigate customer perceptions towards all three dimensions of justice following the failed delivery of a product ordered online. The same study captures customer perceptions of procedural justice towards the firm's offline service recovery procedures of redelivering the ordered product, thus overlooking online recovery procedures. So far, there is no empirical study examining customer perceptions of procedural justice towards online service recovery.

The present study extends prior research by assessing the impact of procedural justice, conveyed by online recovery procedures, on customer post-recovery satisfaction. Online help pages, FAQs and website instructions represent some of the most frequently used procedures firms rely upon when attempting the resolution of online service failures. These online recovery procedures are expected to enable timely and flexible resolution of online service failures, thus conveying procedural justice. Procedural justice delivered online is, in turn, expected to restore customer satisfaction. Accordingly, it is hypothesised that:

H1 Following online service failures, procedural justice perceptions towards online recovery procedures will have a positive impact on customer satisfaction with the recovery encounter.

Interactional justice originates from the field of organisational studies and its main proponents are Bies and Moag (1986). Interactional justice entails perceptions about the 
manner in which outcomes are communicated. In a service recovery situation, interactional justice entails customer perceptions about whether employees treat them fairly (or unfairly). Extant research on offline service failure and recovery recognises employee empathy, politeness and courtesy as key aspects of interactional justice (e.g., Tax et al., 1998; Chebat and Slusarczyk, 2005; Gelbrich and Roschk, 2011). This body of research finds extensive empirical support for the positive impact of interactional justice conveyed by offline service recovery efforts on customer satisfaction (e.g., Blodgett et al., 1997; Smith et al., 1999; del Río-Lanza et al., 2009).

The role of interactional justice in the context of online service failures has, however, been largely overlooked in the literature. A few studies have examined customer preference towards different modes of communicating with the firm, following online service failures. For instance, Ahmad (2002) shows that, following online service failures, customers prefer emails or toll free telephone numbers, over face-to-face communication. Importantly, Ahmad (2002) suggests that customers are most satisfied with service recovery when receiving tailored, rather than pre-composed emails; hence the need for employees to learn how to ‘connect emotionally' with customers (p. 26). Whilst Ahmad (2002) does not measure interactional justice, the author implicitly recognises that interactional justice delivered through email communication is crucial for restoring customer satisfaction following online service failures. Shapiro and Nieman-Gonder (2006) further elaborate on how interactional justice conveyed by the above modes of communication influences customer satisfaction. The above study shows that customers are less satisfied when interacting with the firm via email, rather than in person or over the phone. However, these authors considered offline, rather than online service failures.

In the area of online service failures, Lin et al. (2011) examine the impact of interactional justice on customer satisfaction and word-of-mouth behaviour. The authors 
measure customer reactions to the empathy and politeness shown by employees during the delivery of offline, rather than online, service recovery. The above study, however, does not account for the fact that interactions between customers and employees can take place online and these are mediated by technology (Mazaheri et al., 2012). The way technology is designed can therefore influence customer perceptions. The role of technology-mediated interactions in the context of service recovery encounters, and related perceptions of interactional justice has been thus far overlooked.

The present study adds to prior research by examining the impact of interactional justice, as conveyed by technology-mediated interactions, on customer satisfaction. Instant emails and virtual chat features on websites are examples of technology-mediated interactions increasingly being used by organisations in the energy, hotel, online retailing and telecommunications sectors. This study postulates that the above online tools can be used as online service recovery strategies, and as such, convey the firm's empathy, politeness and concern about the service failure, thus interactional justice. Interactional justice towards online service recovery is, in turn, expected to positively influence customer satisfaction with online service recovery. Thus, it is hypothesised that:

H2 Following online service failures, interactional justice perceptions towards technology-mediated interactions with the employee will have a positive impact on customer satisfaction with the recovery encounter.

\section{The impact of satisfaction with service recovery on behavioural intentions}

The relationship between customer satisfaction with online service recovery and behavioural intentions finds theoretical explanation in the reciprocity norm (Gouldner, 1960). According to this norm, individuals are inclined to help those who have helped them. Prior 
research suggests that customers experience the need to reciprocate the firm when justice is rendered during service recovery (e.g., Grégoire et al., 2009; Van Vaerenbergh et al., 2012). For instance, Grégoire et al. (2009) show that customers who have a good relationship with the firm report lower intentions to take revenge when offered fair, rather than unfair, service recovery. This is explained as the result of customer willingness to reciprocate the justice rendered by the firm during service recovery.

Prior research on offline service failure and recovery provides extensive empirical support for the relationship between customer satisfaction with service recovery, and subsequent positive behavioural intentions (e.g., Blodgett et al., 1997; Smith et al., 1999; Andreassen, 2000; Maxham and Netemeyer, 2002). In the context of online service failures, research has examined the impact of offline service recovery efforts on customer satisfaction and subsequent behavioural intentions. For instance, Holloway et al. (2005) note that customers show intentions to revisit and recommend the firm when satisfied with offline service recovery. Further, Lin et al. (2011) demonstrate that procedural and interactional justice towards offline service recovery attempted following online service failures positively impact satisfaction. However, the same study does not find evidence for the direct impact of perceived justice on negative word of mouth and repatronage intentions. The above finding indicates that satisfaction is a key antecedent of customer post-recovery behavioural intentions. Procedural and interactional justice dimensions thus show a significant impact on behavioural intentions through satisfaction.

In sum, the above research findings relate to online service failure encounters followed by offline service recovery. The present study extends prior knowledge by examining customer satisfaction with online service failure and recovery encounters, and its impact on intentions to switch service provider and recommend the firm to family and friends. In line with prior evidence in the offline context, customers are expected to show 
lower intentions to switch to an alternative service provider and greater intentions to generate PWOM when satisfied with online service recovery. The reciprocity norm (Gouldner, 1960) provides theoretical rationale for the hypothesised effect. When justice is rendered through online service recovery, customers are expected to be satisfied and to show reciprocation to the firm. As evidence of their reciprocation, customers will lower intentions to switch to another firm, and show inclination to generate PWOM. Hence, it is hypothesised that:

H3 Following online service failures, customer satisfaction with online service recovery will have a negative impact on intentions to switch service provider.

H4 Following online service failures, customer satisfaction with online service recovery will have a positive impact on intentions to generate PWOM.

Differential effect of perceived justice in subscription and non-subscription markets

Prior research pinpoints differences in customer perceptions of justice towards offline service recovery across types of service failure. For instance, differential perceptions of justice towards offline service recovery are registered between process and outcome failures (Smith et al., 1999) as well as between high and low severity failures (Maxham and Netemeyer, 2002). For instance, Harris et al. (2006) find that airline customers report greater satisfaction with recovery compensation and repatronage intentions than banking customers. These authors attribute the above finding to the seriousness of the financial implications resulting from failed banking services.

Customer responses to service recovery are also found to differ across service settings. When compared with procedural justice, interactional justice perceptions towards offline service recovery are found to have a greater impact on customer satisfaction in service contexts involving frequent customer-firm interactions, such as hotel services (e.g., Kim et 
al., 2009). By contrast, procedural justice perceptions towards offline service recovery are found to be a strong antecedent to customer satisfaction in the context of cell-phone services, where customer-firm interactions are sporadic and customers are concerned about timely resolution of the failure (e.g., del Río-Lanza et al., 2009).

The present study argues that customer responses to online service recovery are also likely to vary between service contexts. Specifically, differences are hypothesised between subscription or non-subscription services. Such differences are attributed to inherent characteristics of customer-firm relationships in these two contexts. In subscription services, the customer is bound by a contract (e.g., mobile phone contract) and pays a fee on an ongoing basis. In non-subscription services, there is no binding contract, and customers may use the service occasionally. Two contrasting theoretical perspectives can explain the hypothesised differences in customer perceptions of justice towards online service recovery, satisfaction and post-recovery intentions, between subscription and non-subscription services. Each of the two perspectives is discussed below.

The first perspective draws upon the expectancy disconfirmation paradigm (Oliver, 1999). According to this perspective, loyal customers with a history of positive service experiences hold high expectations of the service encounter. Such high expectations form the basis of updating new information, including information conveyed by service failures. Due to their high expectations, this group of customers tends to be difficult to satisfy with service recovery. Customers of subscription services are expected to behave as loyal customers. Specifically, customers of subscription services are likely to hold high expectations of service recovery, due to their ongoing financial investment in paying the subscription fee. Due to their greater expectations, these customers are expected to be more difficult to satisfy following online service failures, than customers of non-subscription services. Based on this theoretical perspective, customers of subscription services will show lower satisfaction with 
online recovery procedures and interactions than customers of non-subscription services. Accordingly, it is hypothesised that:

H5a Following online service failures, the impact of procedural justice perceptions towards online recovery procedures on satisfaction will be weaker in subscription services, than in non-subscription services.

$H 5 b$ Following online service failures, the impact of interactional justice perceptions towards online interactions with the employee on satisfaction will be weaker in subscription services, than in non-subscription services.

A second, contrasting perspective draws upon the literature on brand equity (Aaker, 1991) and it is consistent with research evidence on customer responses to offline service failure and recovery encounters (e.g., Tax et al., 1998). According to this perspective, a history of positive experiences with the firm leads to accumulation of equity. Accumulated equity then functions as a basis of updating new information, such as service failure and recovery encounters. Specifically, customers with a history of positive past experiences with the firm, thus with accumulated equity, tend to discount service failures and poor service recovery efforts and attribute service failures to unstable characteristics of the firm. In this sense, accumulated equity mitigates the negative impact of service failures. As a result, customers with accumulated equity tend to be easier to satisfy.

Extending the above argument to the context of the present study, customers in subscription services are expected to have accumulated equity resulting from their history of past experiences with the firm and from their ongoing financial investment in paying a subscription fee. Accumulated equity is likely to mitigate the negative impact of service failures. Due to the above, customers of subscription services are expected to be easier to 
satisfy following online service failures, than customers of non-subscription services. Accordingly, the present study posits that customers of subscription services will respond more positively to online service recovery and show greater satisfaction, than customers of non-subscription services. Thus, it is hypothesised that:

H6a Following online service failures, the impact of procedural justice perceptions towards online recovery procedures on satisfaction will be stronger in subscription services, than in non-subscription services.

H6b Following online service failures, the impact of interactional justice perceptions towards online interactions with the employee on satisfaction will be stronger in subscription services, than in non-subscription services.

As shown by Bansal et al. (2004), customer commitment to a firm and intentions to maintain the relationship are strongly related to switching costs. As switching costs increase, customers are more likely to show commitment and repatronage intentions. In the mobile phone industry, Polo and Sesé (2009) demonstrate that the characteristics of the customerfirm relationship also greatly influence switching costs. For instance, the length and the depth of the customer-firm relationship increase switching costs as customers gain experience and familiarity with the firm. Due to increased switching costs, customers are less likely to look for an alternative service provider and/or to switch to another firm.

In the context of subscription services, customers are bound by a contract, and therefore show frequent patronage of the subscription service. Due to the length of their relationship with the firm and the frequency of patronage, customers of subscription services are expected to experience high switching costs, consistent with above arguments from prior research. Due to high switching costs, customers of subscription services are expected to 
show lower intentions to switch service provider following online service failure and recovery, than customers of non-subscription services. In subscription services, customer decision to maintain the relationship with the firm is thus expected to be driven by the high costs associated with leaving the service provider, more than by customer satisfaction with online service recovery. Accordingly, it is hypothesised that:

H7 Following online service failures, the impact of customer satisfaction with online service recovery on switching intentions will be weaker in subscription services, than in non-subscription services.

As demonstrated by prior research on offline service failure and recovery, customers engage in word of mouth behaviour (WOM) in an attempt to reduce cognitive dissonance relating to their decision to use the firm in the first instance (e.g., Choi and Choi, 2014). According to the theory of cognitive dissonance (Festinger, 1957), dissonance is a synonym for inconsistency. Cognitive inconsistencies (or dissonance) result, for instance, from engaging in a behaviour that is inconsistent with beliefs. For example, customers may experience cognitive dissonance when smoking, despite holding strong beliefs that smoking damages health. In the context of service failures, cognitive dissonance can arise as customers realise that a service failure could have been avoided, if a different firm had been selected in the first instance.

Cognitive dissonance can also be experienced at the recovery stage, as customers decide to maintain the relationship with the firm, despite being aware that service failures may recur in the future. The present study postulates that the need to reduce cognitive dissonance will be particularly accentuated among customers of subscription services. Following online service failures, customers of subscription services are unlikely to exit the 
relationship with the firm due to high switching costs involved in doing so. Such decision is likely to cause cognitive dissonance, as customers remain with the firm despite believing that alternative, better options are available. In an effort to reduce the cognitive dissonance associated with the decision to maintain the relationship with the firm, these customers are expected to engage in PWOM. Hence, it is hypothesised that:

H8 Following online service failures, the impact of customer satisfaction on intentions to generate PWOM will be stronger in subscription services, than in non-subscription services.

The hypothesised relationships are summarised in the conceptual framework below.

Figure 1: Conceptual framework

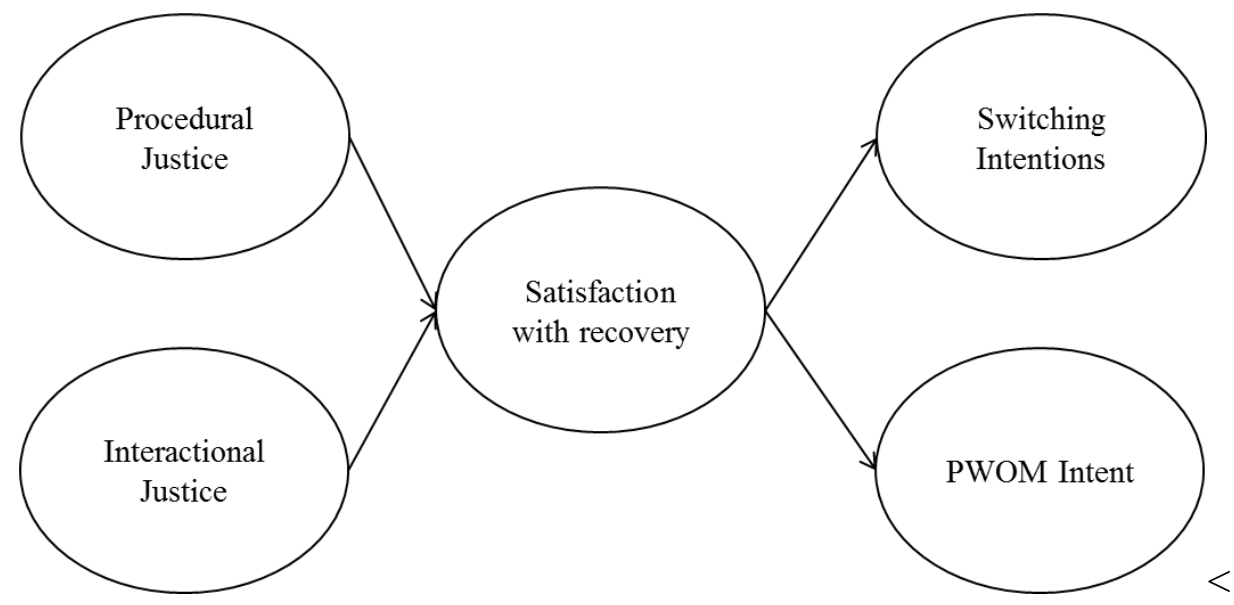

\section{Method}

Design

The study employed a scenario-based experimental design. This approach is suitable for measuring customer perceptions towards naturally occurring events such as service failure and recovery, and it overcomes issues of recall bias typically associated with retrospective self-reporting techniques (Smith et al., 1999). Moreover, scenario-based experiments have been widely used in prior research (e.g., Blodgett et al., 1997; Wirtz and McColl-Kennedy, 
2010). In the context of the present study, hypothetical scenarios of online service failure and recovery with an airtime service provider (subscription) and an online clothing retailer (nonsubscription) were created and embedded into a self-completion questionnaire. The hypothetical scenarios were designed following extensive secondary research focusing on identifying online tools currently employed by retailers and airtime service providers operating online.

Secondary research and discussions with customer services managers at large UK organisations revealed that FAQs pages and other online help (i.e. online discussion forums, instructions) are increasingly being used to encourage customers to solve problems autonomously. Similarly, technology-mediated customer-employee interactions, such as emails and virtual chats, are on the increase. Moreover, recent research in services emphasises the importance of firms in making FAQs pages and best practices stories available on the their website, in an effort to encourage customers to learn about the service and assisting them in enhancing their self-efficacy when using online services (e.g., van Beuningen et al., 2011).

In the mobile airtime context, the service failure depicted the customer signing up online for a mobile phone contract and later discovering that the airtime service was poor and caused several dropped calls. In the online retail context, the service failure scenario depicted the customer experiencing a late delivery of clothing items purchased online. In response to the above online service failures, online service recovery was delivered. The recovery scenarios depicted the customer resolving the service failure with the help of FAQs, online help pages and discussions in online communities providing instructions on how to solve the problem (procedures), as well as by interacting with the employee via the live chat feature on the company's website, and through emails (interactions). 
Based on the above, the scenarios in the questionnaire included the manipulation of two factors: online service recovery tools (online information/mode of contact) and service contexts (subscription/non-subscription). Online information accounted for online help pages, FAQs and online communities/forums. The above tools entail the firm's procedures in handling online service failures without the intervention of service employees. Mode of contact included technology-mediated interactions via the virtual chat, online complaint forms and emails. These tools require the intervention of employees, who interact with customers through technology. After being presented with the online service recovery scenario, respondents were asked to evaluate procedural justice, such as the timeliness of the failure resolution, as well as aspects of interactional justice, including politeness, empathy and concern conveyed by the technology-mediated interactions. Altogether four versions of the questionnaire were employed for data collection. The scenarios included in the questionnaire are presented in Appendix 1.

For data collection, the questionnaire was administered online via electronic survey building software Qualtrics. Each respondent was randomly assigned to one of the four versions of the questionnaire. Respondents were sent a URL link directing them to the online questionnaire. When accessing the questionnaire, respondents were first asked some general questions about their usage frequency and past experience with mobile airtime service providers and online retailers. Some of these questions were included for screening purposes. For instance, only those respondents who reported previously using the online services being examined were retained in the sample and asked to complete the full questionnaire. Next, respondents were presented with the online service failure and recovery scenarios. Finally, after reading the scenarios, respondents were asked to answer questions regarding their perceptions of justice, satisfaction with online service recovery, switching and PWOM intentions. 
Before conducting the main study, a pre-test $(n=30)$ was carried out. The purpose of the pre-test was to establish that the scenarios functioned as expected, and were perceived as realistic, in line with prior experimental research (e.g., Smith et al., 1999; Van Vaerenberg et al., 2012). As part of the realism checks, respondents were asked to indicate the extent to which they thought the situation depicted in the hypothetical scenario could happen in real life and they could imagine themselves as the customer. The service failure and recovery scenarios were perceived as being realistic, thus confirming ecological validity.

\section{The Data}

The respondents were selected through snowball sampling technique. A group of postgraduate students at a UK-based higher education institution were trained to make contact with respondents who matched predefined eligibility criteria. The decision to use a convenience sample was made on the basis of the following two considerations. First, a sampling frame for the population of UK residents using the online services being investigated was not accessible. Second, the researchers set a number of criteria regarding the eligibility of respondents. The respondents were aged above 18 , had been living in the UK for longer than two years, were frequent users of the services being examined and had experienced at least one unsatisfactory service in the past. These criteria narrowed the specificity of the sample characteristics. Hence, selecting a sample that met the eligibility criteria represented a feasible, time and cost-effective solution and the most viable option to obtain a sizeable group of respondents. Moreover, by introducing eligibility criteria, the authors ensured that respondents were familiar with the services being investigated. Due to their familiarity and prior experience of service failure, the respondents were able to easily project themselves in the hypothetical scenarios. In recognition of the fact that bias can be associated with non-probability sampling techniques if subjective judgment influences the 
recruitment of respondents, the postgraduate students were thoroughly trained before starting the recruitment process. The above method was adopted following prior research in this domain (e.g., Weun et al., 2004; Worsfold et al., 2007; Holloway and Beatty, 2008; Wirtz and McColl-Kennedy, 2010).

The size of the sample was determined following the established rule of thumb in partial least squares structural equation modeling (PLS-SEM) analysis, which is used in this study. In this regard, Hair et al. (2014) suggest that when conducting PLS-SEM, the sample size should be equal to or larger than ten times the maximum number of structural paths pointing at a particular construct in the structural model. In the study, the maximum number of structural paths directed at a construct is two, thus the minimum sample size for each scenario was 20 (10x2). Altogether 137 valid responses were obtained, with 67 in subscription services and 70 in non-subscription services.

Overall, the sample was composed of 49 per cent males, 51 per cent females, 25 per cent between the ages of 18-24 years, 40 per cent between the ages of 25-44 years, and 35 per cent aged over 45 years. The majority of respondents reported purchasing products/services online two to three times a month (35 per cent), followed by those who purchase six to eight times a year ( 25 per cent), two to three times a year (10 per cent), and the remaining group reported purchasing online multiple times a week (30 per cent).

\section{Measures}

Items from established multi-item scales, sharing the same construct definition, were borrowed and contextualised keeping in mind the online context of this study. Four items were borrowed from Blodgett et al. (1997), Smith et al. (1999) and del Río-Lanza et al. (2009) to measure procedural justice; three items from Blodgett et al. (1997) and Lin et al. (2011) to measure interactional justice; three items from del Río-Lanza et al. (2009) and Lin 
et al. (2011) to measure customer satisfaction with service recovery; two items from

Davidow (2000) and Lin et al. (2011) to measure switching intentions, and three items from

Blodgett et al. (1997) to measure intentions to generate positive word of mouth were

borrowed and adapted. All items were measured on 7-point, Likert-type scales anchored at

'strongly disagree' and 'strongly agree'. A summary of the adapted measures is provided in

Table 1 below.

Table 1: Measures

\begin{tabular}{|c|c|c|}
\hline Construct(s) & Measurement item(s) & Source(s) \\
\hline $\begin{array}{l}\text { Procedural } \\
\text { Justice }\end{array}$ & $\begin{array}{l}\text { - I think the firm has good online procedures (e.g. FAQs, help pages, } \\
\text { online community) for handling late deliveries/poor airtime service } \\
\text { - By following the firm's online procedures, the problem with the late } \\
\text { delivery/poor airtime service was resolved within a short time period } \\
\text { - Despite the trouble caused by the late delivery/poor airtime service, the } \\
\text { firm's online response seemed adequate } \\
\text { - The online procedures show adequate flexibility of the firm in handling } \\
\text { the late delivery/poor airtime service }\end{array}$ & $\begin{array}{l}\text { del Río-Lanza et } \\
\text { al. (2009); } \\
\text { Blodgett } \text { et al. } \\
\text { (1997); Smith et } \\
\text { al. (1999) }\end{array}$ \\
\hline $\begin{array}{l}\text { Interactional } \\
\text { Justice }\end{array}$ & $\begin{array}{l}\text { - The online communication (e.g., virtual chat and email communication) } \\
\text { showed that the firm is concerned about solving problems with late } \\
\text { deliveries/poor airtime service } \\
\text { - The online communication with the firm was appropriate for handling } \\
\text { the late delivery/poor airtime service } \\
\text { - In solving the problem, the firm's online interaction with me conveyed } \\
\text { courtesy and respect }\end{array}$ & $\begin{array}{l}\text { Blodgett et al. } \\
\text { (1997); Lin } \text { et al. } \\
\text { (2011) }\end{array}$ \\
\hline $\begin{array}{l}\text { Satisfaction } \\
\text { with online } \\
\text { recovery }\end{array}$ & $\begin{array}{l}\text { - I am satisfied with the way the firm handled the problem with the late } \\
\text { delivery/poor airtime services } \\
\text { - Overall, I feel that the firm's online features for handling problems with } \\
\text { late deliveries/poor airtime service are good } \\
\text { - I am satisfied with this firm's online response to my problem }\end{array}$ & $\begin{array}{l}\text { del Río-Lanza et } \\
\text { al. (2009); Lin } e t \\
\text { al. (2011) }\end{array}$ \\
\hline $\begin{array}{l}\text { Switching } \\
\text { Intentions }\end{array}$ & $\begin{array}{l}\text { - I will not switch to another provider because of the late delivery/poor } \\
\text { airtime service [R] } \\
\text { - In the future, I will try to reduce my use of this mobile service/online } \\
\text { retailer due to this inconvenience }\end{array}$ & $\begin{array}{l}\text { Davidow (2000); } \\
\text { Lin et al. (2011) }\end{array}$ \\
\hline $\begin{array}{l}\text { Positive word of } \\
\text { mouth }\end{array}$ & $\begin{array}{l}\text { - I am likely to talk to friends and family about the way the late } \\
\text { delivery/poor airtime service was resolved } \\
\text { - I am likely to share negative opinions about my online experience with } \\
\text { this online retailer/mobile airtime service provider with friends and } \\
\text { family [R] } \\
\text { - I am likely to share positive opinions about my overall online experience } \\
\text { with this online retailer/mobile airtime service provider with friends and } \\
\text { family }\end{array}$ & $\begin{array}{l}\text { Blodgett et al. } \\
\text { (1997) }\end{array}$ \\
\hline
\end{tabular}




\section{Analysis and Results}

In order to test the conceptual framework, PLS- SEM analysis was conducted (Haenlein and Kaplan, 2004; Tenenhaus et al., 2005; Hair et al., 2012) using SmartPLS 3.0 software (Ringle et al., 2014). Given the exploratory nature of the present study and its focus on advancing research in the domain of online service recovery, PLS-SEM was deemed apposite (Chin, 2010). In addition, PLS- SEM allows for testing of the measurement and structural models simultaneously, thereby accounting for measurement error (Streukens et al., 2008). The proficiency of this technique in generating robust results is well-established, especially when using small sample sizes (Hair et al., 2014).

The PLS model estimation provides empirical measures of the relationships between the indicators and the constructs (measurement model), as well as between the constructs (structural model). The analysis typically follows a two-step approach; the first step involves the measurement model assessment, and the second step involves the structural model assessment (Haenlein and Kaplan, 2004; Hair et al., 2012). Accordingly, in this study, the measurement model was first assessed. Internal consistency, reliability and validity are examined when dealing with reflective measurement models, whereas collinearity and content validity measures are relevant to formative measurement models. Since all research constructs in the study had a reflective measurement, internal consistency, reliability and validity were inspected. Second, the structural model was assessed in terms of its predictive accuracy and power, and with respect to the size and significance of the structural paths. Moreover, multi-group analysis (MGA) was carried out in order to test for differences in structural paths between subscription and non-subscription services.

Results from the measurement model assessment are summarised in Table 2. Cronbach's alpha estimates were above the recommended threshold of 0.7 , with the exception of switching intentions $(\alpha=0.674)$. However, composite reliability, considered a 
more robust measure of internal consistency than Cronbach's alpha (Henseler et al., 2009), was consistently above the recommended threshold of 0.7 . Further, item reliability was assessed by inspecting the loadings of each item on the corresponding construct. The loadings were well above the acceptable cut-off point of 0.7 , thus confirming the unidimensionality of the constructs. The exceptions were items 1 and 2 for PWOM, which showed weak loadings (below 0.4) and low average variance extracted (below 0.5). The above two items were removed (following Joireman et al., 2013; Hair et al., 2014), thus PWOM turned into a single-item measure and average variance extracted (AVE) for PWOM exceeded the threshold of 0.50 . The use of a single-item measure for WOM is consistent with prior studies (e.g., Swan and Oliver, 1989; Singh, 1990; File et al., 1994). Once all loadings exceeded the threshold of 0.7 , internal consistency was satisfactory (Hair et al., 2011). Further, AVE for all constructs exceeded 0.5, thus confirming convergent validity (Chin, 1998; Coelho and Henseler, 2012). Finally, discriminant validity was established by using Fornell and Larcker's criterion (1981); the squared correlations of a construct's AVE were higher than their bivariate correlations with other constructs (squared AVE estimates reported in Table 2).

Table 2: Measurement model assessment

\begin{tabular}{lcccc}
\hline & $\begin{array}{c}\text { Cronbach's } \\
\text { Alpha }(\boldsymbol{\alpha})\end{array}$ & $\begin{array}{c}\text { Composite } \\
\text { Reliability }\left(\mathbf{P}_{\mathbf{c}}\right)\end{array}$ & AVE & $\begin{array}{c}\text { Squared } \\
\text { AVE }\end{array}$ \\
\hline Interactional Justice & 0.859 & 0.914 & 0.780 & 0.883 \\
Procedural Justice & 0.869 & 0.911 & 0.718 & 0.848 \\
Satisfaction & 0.932 & 0.957 & 0.880 & 0.938 \\
Switching & 0.674 & 0.857 & 0.750 & 0.866 \\
\hline
\end{tabular}

With regards to the structural model assessment, the variance explained (R-square) for the individual constructs was examined. As shown in Table 3, the proposed model presented substantial explanatory accuracy for customer satisfaction $(\mathrm{R}$-square=0.82), and a weak-tomoderate explanatory accuracy for switching intentions $(\mathrm{R}$-square $=0.39)$ and PWOM $(\mathrm{R}$ square $=0.19)$. Further, the Stone-Geisser's construct cross-validate redundancy measure (Q- 
square) was calculated by means of blindfolding procedure with omission distance set at five cases (Hair et al., 2014). As illustrated in Table 3, all Q-square values were positive and above 0 ; hence, the overall model showed high predictive power.

In order to test for the significance of the structural pathways, a bootstrap resampling analysis with 1,000 sub-samples was carried out (Hair et al., 2014). As shown in Table 3, the individual structural paths were in the hypothesized direction and highly significant. Procedural justice conveyed by online recovery procedures was found to have significant, positive impact on customer satisfaction $(p=.000)$. Interactional justice conveyed by technology-mediated interactions with the employee also showed a significant, positive impact on customer satisfaction ( $p=.000)$. Interactional justice yielded a consistently larger effect than procedural justice in explaining customer satisfaction, as indicated by the large effect size $\left(f^{2}=0.72\right)$. Thus, $\mathrm{H} 1$ and $\mathrm{H} 2$ are supported. Further, customer satisfaction with online service recovery was found to negatively impact switching intentions ( $p=.000)$, but positively influence PWOM ( $p=.000)$. Customer satisfaction with online service recovery yielded a very large effect in explaining switching intentions $\left(f^{2}=0.64\right)$. By contrast, the effect of satisfaction in explaining PWOM was medium to large $\left(f^{2}=0.22\right)$. Overall, H3 and H4 are supported.

Table 3: Structural model assessment

\begin{tabular}{llcc}
\hline Endogenous constructs & Paths(t-values) & $\mathbf{R}^{\mathbf{2}}$ & $\mathbf{Q}^{\mathbf{2}}$ \\
\hline Satisfaction & & 0.816 & 0.716 \\
$\quad$ Interactional Justice $\rightarrow$ Satisf & $0.646(9.74)^{* * *}$ & & \\
$\quad$ Procedural Justice $\rightarrow$ Satisf & $0.294(4.05)^{* * *}$ & & \\
Switching intentions & & 0.389 & 0.284 \\
$\quad$ Satisf $\rightarrow$ Switching & $-0.627(13.62)^{* * *}$ & & \\
PWOM & & 0.185 & 0.172 \\
$\quad$ Satisf $\rightarrow$ PWOM & $0.430(4.94)^{* * *}$ & & \\
\hline Note: *p<.10;**p<.05; ***p<.01; PWOM = Positive Word of Mouth &
\end{tabular}


Subscription and non-subscription services represented two distinct groups. Multigroup analysis (MGA) is typically conducted in order to detect differences in structural paths between sub-populations (or groups) (Henseler and Fassott, 2010). Given the focus of the present study on detecting differences in the hypothesised pathways between subscription and non-subscription services, this technique was deemed suitable. MGA was conducted via bootstrap resampling procedure set at 1,000 resamples, in line with Hair et al. (2014). Results from both parametric and non-parametric approaches to MGA are summarised in Table 4. The findings showed that the impact of interactional justice conveyed by technology-mediated interactions with the employee on customer satisfaction differed between subscription and non-subscription services $(p<.01)$. However, no significant differences between subscription and non-subscription services were observed in relation to the other paths in the model ( $p>.05)$. Thus, H5 is partially supported, whereas H6, H7 and H8 are not supported.

Table 4: Multi-group analysis

\begin{tabular}{lccccrrr}
\hline & \multicolumn{2}{c}{ Subscription } & \multicolumn{2}{c}{ Non-Subscription } & & & \\
& \multicolumn{1}{c}{$\mathrm{p}^{(1)}$} & $\mathrm{se}\left(\mathrm{p}^{(1)}\right)$ & \multicolumn{1}{c}{$\mathrm{p}^{(2)}$} & $\mathrm{se}\left(\mathrm{p}^{(2)}\right)$ & $\left|\mathrm{p}^{(1)}-\mathrm{p}^{(2)}\right|$ & $\begin{array}{c}\text { t-value } \\
(\text { Parametric) }\end{array}$ & $\begin{array}{c}\mathrm{p} \text {-value } \\
(\text { Nonparametric) }\end{array}$ \\
\hline IJ $\rightarrow$ Satisf & 0.536 & 0.089 & 0.769 & 0.085 & 0.234 & $1.903^{*}$ & 0.970 \\
PJ $\rightarrow$ Satisf & 0.392 & 0.097 & 0.193 & 0.094 & 0.194 & 1.446 & 0.077 \\
Satisf $\rightarrow$ Switching & -0.613 & 0.074 & -0.661 & 0.051 & 0.054 & 0.615 & 0.277 \\
Satisf $\rightarrow$ PWOM & 0.561 & 0.109 & 0.317 & 0.127 & 0.244 & 1.465 & 0.073 \\
\hline
\end{tabular}

Note: IJ = Interactional Justice; PJ = Procedural Justice; PWOM = Positive Word of Mouth

\section{Discussion and Conclusions}

Service firms operating online often encounter online service failures. Understanding how to recover from online service failures is crucial for service managers in order to design effective service recovery strategies. Although research on consumer online service experiences is growing, little is known about how firms can deliver online service recovery and the impact of online service recovery on customer perceptions and post-recovery 
behaviour. The present study attempted to address the above research gap and examined how two online tools, namely online information and technology-mediated communication, function as online service recovery strategies. Specifically, the study assessed customer perceptions of justice towards the above two online service recovery strategies, and the impact of perceived justice on customer post-recovery satisfaction, and behavioural intentions. Additionally, differences in customer responses to online service recovery between subscription and non-subscription services were assessed.

The study's findings reveal that online tools on the company's website are effective service recovery strategies when addressing customer needs for justice. Customers show perceptions of procedural justice when online procedures in the form of FAQs, online help pages and discussion forums enable timely resolution of the service failure. Similarly, customers show interactional justice perceptions when technology-mediated interactions with the employee convey politeness, empathy and concern about the service failure. Perceived justice conveyed by online service recovery strategies in turn restores customer satisfaction. The above finding is consistent with previous evidence on offline service recovery showing perceived justice towards offline recovery to be a predictor of customer satisfaction with recovery (e.g., Tax et al., 1998; Smith et al., 1999; Maxham and Netemeyer, 2002). This study extends prior research by demonstrating that service recovery can be implemented through online tools such as online information and technology-mediated communication. Importantly, if designed effectively, these tools are perceived to be fair. Perceived fairness (justice) towards online service recovery is a key driver of customer satisfaction with online service failure and recovery encounters. Overall, these findings establish the relevance of the justice framework in explaining customer responses to online service failures followed by online recovery. 
Remarkably, interactional justice conveyed by technology-mediated forms of communication is found to be a strong determinant of customer satisfaction with online service recovery, even more than procedural justice conveyed by online recovery procedures. The above result is consistent with the assertions by Ahmad (2002) that customers are satisfied with service recovery when receiving tailored emails and when feeling emotionally connected with employees. Even in the context of technology-mediated interactions with employees, customers seem to value customised interpersonal treatment. The above finding is consistent with prior research evidence on offline service recovery suggesting that empathy, politeness and concern about the failure conveyed by frontline employees during face-to-face interactions are crucial for restoring customer confidence in the firm (e.g., Kim et al., 2009).

Furthermore, the study's findings confirm that customer satisfaction restored by means of online service recovery discourages customers from switching to another service provider, yet encourages them to generate PWOM. This finding is consistent with the reciprocity norm (Gouldner, 1960) and prior evidence in the domain of offline service failure and recovery encounters (e.g., Blodgett et al., 1997; Grégoire et al., 2009). Customers expect the firm to render justice by means of online service recovery and they reciprocate justice by showing willingness to maintain the relationship with the firm (low switching intentions) and to generate PWOM.

Differences in customer perceptions of justice are noted between subscription and non-subscription services. Specifically, the impact of interactional justice conveyed by technology-mediated interactions with the employee on satisfaction is weaker in subscription services, than in non-subscription services. This finding provides support for the perspective from the expectancy disconfirmation paradigm (Oliver, 1999). Based on this perspective, customers of subscription services have expectations of service recovery which are greater 
than those held by customers of non-subscription services, especially in reference to the fairness of treatment. This could be attributed to the ongoing financial investment customers incur when dealing with subscription services, wherein a subscription fee is paid. Importantly, the above finding suggests that these customers are likely to be more difficult to satisfy following online service failures, than customers of non-subscription services.

The positive impact of procedural justice conveyed by online recovery procedures on customer satisfaction, however, does not differ between subscription and non-subscription services. Customers seem to equally value timely resolution of the online service failure and flexible recovery procedures, in both subscription and non-subscription service contexts. The lack of significant differences between subscription and non-subscription services in relation to procedural justice can be attributed to customers perceiving online help pages and FAQs to be fairly standardised across organisations and service sectors. Accordingly, customer perceptions of procedural justice conveyed by online recovery procedures varied little across subscription and non-subscription services, thus no significant differences in procedural justice were detected.

Finally, the findings reveal no differences in customer switching and PWOM between subscription and non-subscription services. Customers of subscription services thus do not show lower intentions to switch service provider than customers of non-subscription services, due to the costs involved in exiting the subscription contract. Moreover, their intentions to generate PWOM do not seem to be triggered by the need to reduce cognitive dissonance, but by satisfactory online service recovery. Both groups of customers are mainly concerned about receiving satisfactory online recovery, following online service failures. In sum, the above discussion indicates that customer intentions to switch and/or generate PWOM following online service failure and recovery are driven by the online recovery experience, more than by the service context, whether subscription or non-subscription. 


\section{Theoretical and Practical Implications}

The study's findings offer important theoretical and managerial implications. First, prior research has extensively examined how firms can deliver offline service recovery, and consequent customer perceptions of justice. By contrast, situations when online services fail and online service recovery is attempted have been overlooked. There is an emerging body of research focusing on online service failures following which offline service recovery is delivered (e.g., Holloway et al., 2005; Harris et al., 2006; Lin et al., 2011). However, research investigating how firms can rectify online service failures through the implementation of online recovery tools is still scarce. Accordingly, little attention has been directed towards customer responses to service failure and recovery encounters taking place online. The present study advances research in the area of service failure and recovery management by providing empirical evidence that customers perceive online information such as FAQ pages, help pages, and discussion forums, as fair procedures of handling online service failures when these lead to fast problem resolution. Further, evidence is provided that technology-mediated communication is an effective online recovery strategy, when addressing customer needs for self-esteem.

The above findings suggest that the way websites and other online tools are designed influences customer responses to unsatisfactory online service encounters. Further, the findings indirectly provide support to evidence in the offline context showing that customers can actively participate in offline service recovery encounters, thus becoming co-creators of service recovery (e.g., Dong et al., 2008). In the online environment, customer participation may entail following guidelines from online help pages or discussion forums, or engaging in technology-mediated conversations with service employees like live chat conversations. 
Research on online service recovery management should, therefore, take into consideration the roles of website design and customer participation in the delivery of service recovery.

Second, prior literature in service failure and recovery widely recognises the relevance of the justice framework in explaining effective service recovery efforts delivered offline (e.g., Tax et al., 1998; Smith et al., 1999; Chebat and Slusarczyk, 2005; del Río-Lanza et al., 2009). The present study establishes the efficacy of the justice framework in understanding customer responses to online service failures followed by online service recovery. Perceived fairness towards online service recovery is shown to foster satisfaction, and in turn, loyal behaviour. In particular, interactional justice conveyed by technologymediated communication influences customer satisfaction with online service recovery, more than procedural justice conveyed by online procedures. From a theoretical standpoint, the above findings suggest that perceptions of justice towards online recovery are crucial for explaining customer retention. Studies in this domain should therefore consider the role played by justice perceptions when examining customer attitudes and behavioural intentions following online service recovery.

For online service providers, customer perceptions of procedural justice conveyed by online information indicate that FAQs and discussion forums are perceived to be timely recovery procedures. Consistent with the suggestions by van Beuningen et al. (2011), online retailers and airtime service providers are recommended to design websites in such a way that customers are encouraged to learn about the service and about how to resolve online service failures. Towards this aim, online instructions should be made simple and easy-to-access. Furthermore, the large effect of interactional justice on customer post-recovery satisfaction highlights the need for service managers to allocate resources towards carefully designing technology-mediated forms of communication. Writing bespoke rather than standardised emails that communicate politeness and empathy to customers, and training 
customer services staff on the live chat to deliver interactional justice will ensure that customers are satisfied with online service recovery.

Third, this study demonstrates that customers report differential perceptions of justice depending on whether subscription or non-subscription services fail. In particular, interactional justice conveyed by technology-mediated interactions with employees contributes to restoring customer satisfaction, in the context of non-subscription services more than in subscription services. This finding shows the importance of considering the characteristics of the service context and the type of customer-firm relationship when examining customer perceptions of online service failure and recovery encounters. The distinction between subscription and non-subscription markets provides a useful framework for future research.

In addition, from a managerial perspective, the findings illustrate the need for companies providing non-subscription services to design technology-mediated communication that meets customer needs for empathy and politeness. In non-subscription services, interactional justice conveyed during technology-mediated interactions is particularly influential in shaping customer satisfaction. In subscription services, on the other hand, standardised technology-mediated communication can be employed.

\section{Limitations and Further Research}

The conclusions from this study's findings are drawn with the caveats of experimental research and non-probability sampling. The study's limitations, however, present important avenues for future research. First, the study's sample included frequent users of the services being examined, who had experienced at least one service failure in the past. An interesting avenue for future research is to test whether this study's findings can be extended to the general population of users of online services, and to other contexts. For instance, online 
banking, auctions and education are increasingly being used and thus deserve greater attention. Second, the study adopted an experimental research design, which ensures high internal validity of findings and it has been widely used in prior research. For external validity purposes, realism and manipulation checks were conducted as part of the pre-tests. In real life situations, customer individual characteristics, such as their level of self-efficacy, may also influence responses to online service recovery. Future research can, therefore, investigate the role of customer characteristics, and conduct a field study to confirm the external validity of findings.

Third, results from this study indicate that customer satisfaction with online service recovery explains little variance for switching and PWOM intentions. Future studies could measure other relevant constructs, such as trust and commitment, along with satisfaction. Prior research pinpoints the importance of trust in encouraging customers to revisit websites and to repurchase from the same online service provider (e.g., Ribbink et al., 2004).

Fourth, this study takes a cross-sectional approach to understanding how customers respond to online service failures followed by online service recovery. Future research may employ a longitudinal research design to shed light on how customer perceptions of justice towards online service recovery, satisfaction and post-recovery behaviour change as customers become familiar with the company's online recovery tools. Fifth, this study deduces that customers can be asked to participate in the process of handling online service failures, for instance, by following instructions on online help pages. Future studies could contribute to extant research on the role of customers as co-creators in services (e.g., Dong et al., 2008; Roggeveen et al., 2012) by examining customer co-creation of online service recovery. Lastly, future research might consider the perspectives from services and information technology literature streams in the attempt to unravel the complexities involved in delivering online service recovery, wherein human-computer interactions are involved. 


\section{Appendix 1: Scenarios}

\section{Scenario 1: Mode of contact, subscription service}

You recently bought a new phone, changed your mobile service provider and signed up online for a 12month contract. After a few weeks you discover that your phone rarely has service and that it drops a lot of calls. You go to the mobile service provider's website to find information on how the problem can be fixed. The website provides a chat line where you chat with an employee, virtually. You explain the problem to the employee. In response, the employee apologises for the inconvenience and confirms that there may be a problem of outage in the area. You are then advised to wait 24 hours for the problem to be fixed. A day later, you receive a polite email from an employee confirming that the problem has been fixed.

\section{Scenario 2: Online information, subscription service}

You recently bought a new phone, changed your mobile service provider and signed up online for a 12month contract. After a few weeks you discover that your phone rarely has service and that it drops a lot of calls. You go to the mobile service provider's website to find information on how the problem can be fixed. The website provides FAQs and an online help guide but these do not help you in solving the problem. You look through the FAQs and the discussions in the online community, and you find a solution to your problem.

\section{Scenario 3: Mode of contact, non-subscription service}

You recently purchased some clothes online. At the time of purchase, you received an email confirmation stating that the items would be delivered within the following day. After four days you still have not received your items. The website provides a chat line where you chat with an employee, virtually. You explain the problem to the employee. In response, the employee apologises for the inconvenience and confirms that they have experienced some delivery problems and that your order will be delivered to you within the following two days. After an hour, an employee at the company emails you back apologising for the inconvenience and confirming that the items are with the courier, ready to be delivered. You receive your items two days later.

\section{Scenario 4: Online information, non-subscription service}

You recently purchased some clothes online. At the time of purchase, you received an email confirmation stating that the items would be delivered within the following day. After four days you still have not received your items. You therefore decide to go to the retailer's website to find a solution to the problem. The website provides online FAQs with reasons why the delivery of items ordered online may be delayed. Whilst going through the FAQs, you find out that customers are recommended to fill out an online complaint form detailing the problem and Customer Services will deal this with if the items take longer than a week to be delivered. You therefore fill out the online complaint form and ask about your order. Yet, you receive your items two days later. 


\section{References}

Aaker, D.A. (1991), Managing Brand Equity, The Free Press, New York, NY.

Ahmad, S. (2002), "Service failures and customer defection: a closer look at online shopping experiences", Managing Service Quality, Vol. 12 No. 1, pp. 19-29.

Andreassen, T.W. (2000), "Antecedents to satisfaction with service recovery", European Journal of Marketing, Vol. 34 No. 1/2, pp. 156-175.

Bansal, H.S., Irving, P.G. and Taylor, S.F. (2004), “A three-component model of customer commitment to service providers", Journal of the Academy of Marketing Science, Vol. 32 No. 3, pp. 234-250.

Bartl, C., Gouthier, M.H.J. and Lenker, M. (2013), "Delighting consumers click by click. Antecedents and effects of delight online", Journal of Service Research, Vol. 16 No. 3, pp. 386-399.

Bies, R.J. and Moag, J.S. (1986), "Interactional justice: Communication criteria of fairness", in Lewicki, R.J., Sheppard, B.H. and Bazerman M.H. (Eds.), Research on negotiation in organizations, Vol. 1, JAI Press, Greenwich, CT, pp. 43-55.

Bitner, M.J., Booms, B.H. and Tetreault, M.S. (1990), “The Service Encounter: Diagnosing Favorable and Unfavorable Incidents", Journal of Marketing, Vol. 54 No. 1, pp. 71-84.

Blodgett, J.G., Hill, D.J., and Tax, S.S. (1997), "The effects of distributive, procedural, and interactional justice on postcomplaint behavior", Journal of Retailing, Vol. 73 No. 2, pp. 185-210.

Chebat, J.C. and Slusarczyk, W. (2005), "How emotions mediate the effects of perceived justice on loyalty in service recovery situations: an empirical study", Journal of Business Research, Vol. 58 No. 5, pp. 664-673.

Chin, W.W. (1998), “The Partial Least Squares Approach to Structural Equation Modeling”, In Marcoulides, G.A. (Ed.), Modern Methods of Business Research, Lawrence Erlbaum Associates, London, pp. 295-333.

Chin, W.W. (2010), "How to Write Up and report PLS Analyses," in Vinzi, V.E., Chin, W.W., Henseler, J. and Wang, H. (eds.), Handbook of Partial Least Squares, SpringerVerlag, Berlin, pp. 655-690.

Choi, B. and Choi, B.J. (2014), "The effects of perceived service recovery justice on customer affection, loyalty, and word-of-mouth", European Journal of Marketing, Vol. 48 No. $1 / 2$, pp. $108-131$.

Coelho, P.S. and Henseler, J. (2012), "Creating customer loyalty through service customization”, European Journal of Marketing, Vol. 46 No. 3/4, pp. 331-356.

Davidow, M. (2000), "The bottom line impact of organizational responses to customer complaints", Journal of Hospitality \& Tourism Research, Vol. 24 No. 4, pp. 473-490.

del Río-Lanza, A.B., Vázquez-Casielles, R. and Díaz-Martín, A.M. (2009), "Satisfaction with service recovery: Perceived justice and emotional response", Journal of Business Research, Vol. 62 No. 8, pp. 775-781.

Dong, B., Evans, K.R. and Zou, S. (2008), "The effects of customer participation in cocreated service recovery", Journal of the Academy of Marketing Science, Vol. 36 No. 1, pp. 123-137. 
Festinger, L. (1957), A theory of cognitive dissonance, Stanford University Press, Stanford, CA.

File, K.M., Cermak, D.S.P. and Prince, R.A. (1994), "Word-of-mouth effects in professional services buyer behaviour", The Service Industries Journal, Vol. 14 No. 3, pp. 301-314.

Fornell, C. and Larcker, D.F. (1981), "Structural equation models with unobservable variables and measurement error: Algebra and statistics", Journal of Marketing Research, Vol. 18 No. 3, pp. 382-388.

Gelbrich, K. and Roschk, H. (2011), “A meta-analysis of organizational complaint handling and customer responses", Journal of Service Research, Vol. 14 No. 1, pp. 24-43.

Gouldner, A.W. (1960), "The norm of reciprocity: A preliminary statement", American Sociological Review, Vol. 25 No. 2, pp. 161-178.

Grégoire, Y., Tripp, T.M. and Legoux, R. (2009), "When customer love turns into lasting hate: The effects of relationship strength and time on customer revenge and avoidance", Journal of Marketing, Vol. 73 No. 6, pp. 18-32.

Haenlein, M. and Kaplan, A.M. (2004), “A beginner's guide to partial least squares analysis”, Understanding Statistics, Vol. 3 No. 4, pp. 283-297.

Hair, J.F., Hult, G.T.M., Ringle, C.M. and Sarstedt, M. (2014), A Primer On Partial Least Squares Structural Equation Modeling (PLS-SEM), SAGE Publications, Thousand Oaks, CA.

Hair, J.F., Ringle, C.M. and Sarstedt, M. (2011), "PLS-SEM: Indeed a silver bullet", Journal of Marketing Theory and Practice, Vol. 19 No. 2, pp. 139-152.

Hair, J.F., Sarstedt, M., Ringle, C.M. and Mena, J.A. (2012), "An assessment of the use of partial least squares structural equation modeling in marketing research", Journal of the Academy of Marketing Science, Vol. 40 No. 3, pp. 414-433.

Harris, K.E., Grewal, D., Mohr, L.A. and Bernhardt, K.L. (2006), "Consumer responses to service recovery strategies: The moderating role of online versus offline environment", Journal of Business Research, Vol. 59 No. 4, pp. 425-431.

Henseler, J. and Fassott, G. (2010), "Testing moderating effects in PLS path models: An illustration of available procedures", in Esposito Vinzi, V., Chin, W.W., Henseler, J. and Wang, H. (Eds.), Handbook of partial least squares. Concepts, methods and applications, Springer-Verlag Berlin, Heidelberg, pp. 713-735.

Henseler, J., Ringle, C.M. and Sinkovics, R.R. (2009), "The use of partial least squares path modeling in international marketing", New Challenges to International Marketing. Advances in International Marketing, Vol. 20, pp. 277-319.

Holloway, B.B. and Beatty, S.E. (2003), "Service failure in online retailing: A recovery opportunity”, Journal of Service Research, Vol. 6 No. 1, pp. 92-105.

Holloway, B.B., Wang, S. and Parish, J.T. (2005), "The role of cumulative online purchasing experience in service recovery management”, Journal of Interactive Marketing, Vol. 19 No. 3, pp. 54-66.

Holloway, B.B. and Beatty, S.E. (2008), "Satisfiers and dissatisfiers in the online environment: A critical incident assessment", Journal of Service Research, Vol. 10 No. 4, pp. 347-364. 
Homans, G.C. (1961), Social behaviour. Its elementary forms, Routledge \& Kegan Paul, London.

Karatepe, O.M. (2006), "Customer complaints and organizational responses: The effects of complainants' perceptions of justice on satisfaction and loyalty", International Journal of Hospitality Management, Vol. 25 No. 1, pp. 69-90.

Key Note (2013), “Home Shopping 2013”, available at: http://www.keynote.co.uk/marketintelligence/view/product/10666/home-shopping (accessed 3 December 2013)

Kim, T.T., Kim, W.G. and Kim, H.B. (2009), "The effects of perceived justice on recovery satisfaction, trust, word-of-mouth, and revisit intention in upscale hotels", Tourism Management, Vol. 30 No. 1, pp. 51-62.

Joireman, J., Grégoire, Y., Devezer, B. and Tripp, T.M. (2013), "When do customers offer firms a "second chance" following a double deviation? The impact of inferred firm motives on customer revenge and reconciliation", Journal of Retailing, Vol. 89 No. 3, pp. 315-337.

Lin, H.H., Wang, Y.S. and Chang, L.K. (2011), "Consumer responses to online retailer's service recovery after a service failure: A perspective of justice theory", Managing Service Quality, Vol. 21 No. 5, pp. 511-534.

MarketingCharts Staff (2013), "Bad Customer Service Interactions More Likely to be Shared Than Good Ones", 15 April, available at: http://www.marketingcharts.com/wp/interactive/bad-customer-service-interactionsmore-likely-to-be-shared-than-good-ones-28628/ (accessed 9 December 2013)

Mazaheri, E., Richard, M.O. and Laroche, M. (2012), "The role of emotions in online consumer behaviour: a comparison of search, experience and credence services", Journal of Services Marketing, Vol. 26 No. 7, pp. 535-550.

Maxham III, J.G. and Netemeyer, R.G. (2002), "Modeling customer perceptions of complaint handling over time: the effects of perceived justice on satisfaction and intent", Journal of Retailing, Vol. 78 No. 4, pp. 239-252.

Meuter, M.L., Bitner, M.J., Ostrom, A.L. and Brown, S.W. (2005), "Choosing among alternative service delivery modes: an investigation of customer trial of self-service technologies", Journal of Marketing, Vol. 69 No. 2, pp. 61-83.

Mintel (2015), “Online Grocery Retailing”, available at: http://oxygen.mintel.com (accessed 30 April 2015).

Mintel (2014), “Online Clothing Retailing”, available at: http://oxygen.mintel.com (accessed 30 March 2015).

Oliver, R.L. (1999), “Whence customer loyalty?”, Journal of Marketing, Vol. 63 (Special Issue), pp. 33-44.

Parasuraman, A., Zeithaml, V.A. and Malhotra, A. (2005), "E-S-QUAL: A multiple-item scale for assessing electronic service quality", Journal of Service Research, Vol. 7 No. 3, pp. 213-233.

Polo, Y. and Sesé, F.J. (2009), "How to make switching costly: The role of marketing and relationship characteristics", Journal of Service Research, Vol. 12 No. 2, pp. 119-137. 
Ribbink, D., van Riel, A.C.R., Liljander, V. and Streukens, S. (2004), "Comfort your online customer: quality, trust and loyalty on the internet", Managing Service Quality, Vol. 14 No. 6, pp. 446-456.

Ringle, C.M., Wende, S. and Becker, J.M. (2014), SmartPLS 3, SmartPLS, Hamburg. Retrieved from http://www.smartpls.com

Roggeveen, A.L., Tsiros, M. and Grewal, D. (2012), "Understanding the co-creation effect: when does collaborating with customers provide a lift to service recovery?", Journal of the Academy of Marketing Science, Vol. 40 No. 6, pp. 771-790.

Roschk, H. and Kaiser, S. (2013), "The nature of an apology: An experimental study on how to apologize after a service failure", Marketing Letters, Vol. 24 No. 3, pp. 293-309.

Schumann, J.H., Wünderlich, N.V. and Wangenheim, F. (2012), "Technology mediation in service delivery: A new typology and an agenda for managers and academics", Technovation, Vol. 32 No. 2, pp. 133-143.

Shapiro, T. and Nieman-Gonder, J. (2006), "Effect of communication mode in justice-based service recovery", Managing Service Quality, Vol. 16 No. 2, pp. 124-144.

Singh, J. (1990), "Voice, exit, and negative word-of-mouth behaviors: An investigation across three service categories", Journal of the Academy of Marketing Science, Vol. 18 No. 1, pp. 1-15.

Smith, A.K., Bolton, R.N. and Wagner, J. (1999), "A model of customer satisfaction with service encounters involving failure and recovery", Journal of Marketing Research, Vol. 36 No. 3, pp. 356-372.

Sparks, B.A. and McColl-Kennedy, J.R. (2001), "Justice strategy options for increased customer satisfaction in a services recovery setting", Journal of Business Research, Vol. 54 No. 3, pp. 209-218.

Streukens, S., Wetzels, M., Daryanto, A. and de Ruyter, K. (2010), “Analyzing factorial data using PLS: Application in an online complaining context”, in Vinzi, V.E., Chin, W.W., Henseler, J. and Wang, H. (eds), Handbook of Partial Least Squares: Concepts, methods and applications, Springer-Verlag, Heidelberg.

Swan, J.E. and Oliver, R.L. (1989), "Postpurchase communications by consumers", Journal of Retailing, Vol. 65 No. 4, pp. 516-533.

Tax, S.S., Brown, S.W. and Chandrashekaran, M. (1998), "Customer evaluations of service complaint experiences: Implications for relationship marketing”, Journal of Marketing, Vol. 62 No. 2, pp. 60-76.

Tenenhaus , M., Vinzi, V.E., Chatelin, Y.M. and Lauro, C. (2005), "PLS path Modeling", Computational Statistics \& Data Analysis, Vol. 48 No. 1, pp. 159-205.

Thibaut, J. and Walker, L. (1975), Procedural justice: A psychological analysis, Lawrence Erlbaum Associates, Hillsdale, NJ.

van Beuningen, J., de Ruyter, K. and Wetzels, M. (2011), “The power of self-efficacy change during service provision: Making your customers feel better about themselves pays off", Journal of Service Research, Vol. 14 No. 1, pp. 108-125.

Van Vaerenbergh, Y., Larivière, B. and Vermeir, I. (2012), “The impact of process recovery communication on customer satisfaction, repurchase intentions, and word-of-mouth intentions", Journal of Service Research, Vol. 15 No. 3, pp. 262-279. 
Weun, S., Beatty, S.E. and Jones, M.A. (2004), "The impact of service failure severity on service recovery evaluations and post-recovery relationships", Journal of Services Marketing, Vol. 18 No. 2, pp. 133-146.

Wirtz, J. and McColl-Kennedy, J.R. (2010), “Opportunistic customer claiming during service recovery”, Journal of the Academy of Marketing Science, Vol. 38 No. 5, pp. 654-675.

Worsfold, K., Worsfold, J. and Bradley, G. (2007), "Interactive effects of proactive and reactive service recovery strategies: The case of rapport and compensation", Journal of Applied Social Psychology, Vol. 37 No. 11, pp. 2496-2517. 


\section{Author Biographical Details:}

Dr Jaywant Singh is Associate Professor in Marketing at Kingston Business School, Kingston University London (UK). His research interests are in the areas of consumer behaviour, branding and services marketing. He has published, amongst others, in the Journal of Advertising Research, Journal of Business Ethics, Marketing Letters, European Journal of Marketing, Journal of Business Research, Industrial Marketing Management, International Journal of Market Research, and the Journal of Business \&Industrial Marketing.

Benedetta Crisafulli is a PhD candidate in marketing at the Department of Strategy, Marketing and Innovation at Kingston Business School, Kingston University London (UK). Benedetta studied at Ruprecht-Karls-Universität Heidelberg (Germany) and the University of Siena (Italy), where she received her BA (Honours). She completed her MA in Marketing, and MSc in Management and Business Studies Research at Kingston University London, with distinction. Benedetta's research focus is in consumer behaviour and services marketing, with a focus on the psychology of consumers during service failure and recovery encounters.

\section{Acknowledgements:}

The authors are grateful to the two anonymous reviewers for their helpful comments, and Rike Mikkelson for her help in data collection. 